\title{
BIOCARBON FROM DIFFERENT BIOMASS PRECURSORS
}

\author{
Kalina Miteva, Georgi Georgiev, Ivanka Stoycheva, Nartzislav Petrov, \\ Bilyana Petrova, Andrei Sarbu, Boyko Tsyntsarski
}

\begin{abstract}
Thermochemical conversion of lignocellulosic biomass is considered as a good opportunity to obtain liquid raw materials for biofuels and biochemicals. During this pyrolysis process a solid product, biocarbon, is obtained. Nowadays there is a growing interest in biocarbon, due to the potential benefits of its application in soil as a stimulant and $\mathrm{CO}_{2}$ trap. The physicochemical and porous properties of biocarbon are suitable for development of effective and inexpensive sorbents for the removal of contaminants from water. Biocarbon has promising sorption properties for various pollutants in water, including polycyclic aromatic hydrocarbons and heavy metals. Banana and orange peels, as well as cocoa flakes, were used as precursors. The carbonization was carried out at temperatures from $500^{\circ} \mathrm{C}$ to $900^{\circ}$ C. Some of the samples were subjected to physical and chemical activation. The obtained carbon adsorbents are characterized by adsorption of iodine, BET, etc. It is planned to study the possibilities for the successful application of the obtained carbon materials as adsorbents for water and air purification, catalysts, hydrogen depots, etc.
\end{abstract}

\section{INTRODUCTION}

Thermochemical conversion of lignocellulosic biomass has been considered as a viable option to produce intermediate liquid streams for biofuels and biochemicals. During the conversion process, biocarbon is generated as a by-product of pyrolysis; its optimization and application is essential to make the overall process economically feasible. Pyrolysis engineers have traditionally sought to minimize char production, as it has been considered as a low-value fraction, decreasing the yield of bio-oil. Recently, there is a growing interest in biocarbon due to the potential benefits of its application to soil as carbon sequestration and soil amendment [1-3]. The physicochemical and porous properties of biocarbon are attractive for the development of effective and lowcost sorbents for removal of water contaminants. Biocarbon has promising sorption properties for various contaminants of water including polycyclic aromatic hydrocarbons and heavy metals [4-7].

The subject of this paper is production of biocarbon from different biomass precursors. The physicochemical and porous properties of biocarbon are suitable for development of effective and inexpensive sorbents for the removal of contaminants from water.

\section{MATERIALS AND METHODS}

Different biomass materials are used as precursors for biocarbon - banana peels, orange peels and cocoa husk. Fruit biomass materials are crashed to smaller pieces, dried and subjected to carbonization at $500^{\circ} \mathrm{C}$. Further chemical activation with $\mathrm{KOH}$ and $\mathrm{K}_{2} \mathrm{CO}_{3}$, and subsequent activation at $550-800^{\circ} \mathrm{C}$ were carried out. Biocarbon samples are synthesized after hydropyrolysis and $\mathrm{CO}_{2}$ activation at temperatures $550-750^{\circ} \mathrm{C}$, and different duration (1-3 h). Synthesis scheme is depicted on Fig. 1.

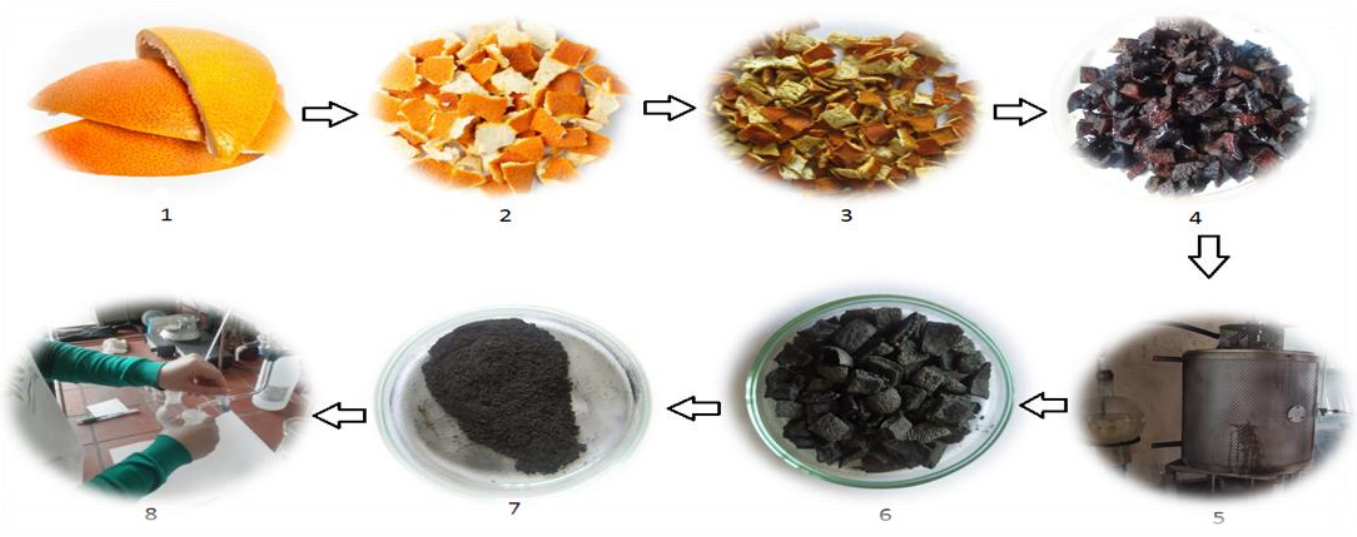

Fig. 1. Synthesis of biocarbon from orange peels

1 - orange peels, 2 - crashed orange peels, 3 - dried orange peels, 4 - carbonizate after chemical activation with $\mathrm{K} 2 \mathrm{CO} 3,5$ - hydro-pyrolysis at $550-750{ }^{\circ} \mathrm{C}$ in stainless-steel reactor in tube furnace, 6 - obtained biocarbon, 7 - grinded biocarbon, 8 - characterization of obtained biocarbon by iodine adsorption. 
The porous structure of carbon samples is studied by nitrogen physisorption at $77 \mathrm{~K}$ using Quantachrome Instruments Quantachrome Autosorb ASiQwin (USA) apparatus. The specific surface area is determined from Brunauer-Emmett-Teller (BET) equation, the total pore volume was obtained at a relative pressure of 0.99 , the micropores volume was elucidated by V-tmethod. The mesopore size distribution is performed by Non-Localized Density Functional Theory (NLDFT) method, using slit shape pore assumption for carbons, and the micropore size distribution is calculated by the Dubinin-Astakhov (DA) method.

\section{RESULTS AND DISCUSSION}

Elemental analysis is shown in Table 1.

Table 1. Elemental analysis of obtained biocarbons

\begin{tabular}{|c|c|c|c|c|c|c|c|}
\hline Sample & $\mathbf{W}^{\mathrm{a}} \%$ & $\mathbf{A}^{\mathbf{d}} \%$ & $\mathbf{C} \%$ & $\mathbf{H} \%$ & $\mathbf{N} \%$ & $\mathbf{S} \%$ & $\mathbf{O} \%$ \\
\hline BC-OP & 2.04 & 11.0 & 79.05 & 4.11 & 1.23 & 0.03 & 15.58 \\
\hline BC-CH & 1.8 & 13.1 & 84.7 & 1.3 & 1.6 & 0.3 & 12.1 \\
\hline BC-BP & 1.7 & 2.6 & 78 & 2.5 & 1.1 & 0.5 & 17.9 \\
\hline
\end{tabular}

The results from iodine adsorption show that various biocarbons obtained are characterized by moderate and high adsorption capacity (200-900 mg/g). Banana peel based biocarbon is distinguished by very high iodine adsorption value of $910 \mathrm{mg} / \mathrm{g}$.
Orange peel based biocarbon demonstrates much lower iodine adsorption capacity of $421 \mathrm{mg} / \mathrm{g}$. Cocoa based biocarbon is characterized by moderate adsorption capacity of $703 \mathrm{mg} / \mathrm{g}$.

Table 2. Textural characteristics of obtained biocarbons

\begin{tabular}{|c|c|c|c|c|c|}
\hline Sample & $\begin{array}{c}\text { Iodine } \\
\text { adsorption, } \\
\mathrm{mg} / \mathrm{g}\end{array}$ & $\begin{array}{l}S_{\text {BET }} \\
\mathrm{m}^{2} / \mathrm{g}\end{array}$ & $\begin{array}{c}V_{\mathrm{t}} \\
3 \\
\mathrm{~cm}^{3} / \mathrm{g}\end{array}$ & $\begin{array}{c}V_{\text {mi }} \\
\mathrm{cm}^{3} / \mathrm{g}\end{array}$ & $\begin{array}{l}V_{\text {meso }} \\
\mathrm{cm}^{3} / \mathrm{g}\end{array}$ \\
\hline $\begin{array}{c}\text { Biocarbon from } \\
\text { banana peel } \\
\text { BC-BP } \\
\end{array}$ & 910 & 820 & 0.47 & 0.37 & 0.05 \\
\hline $\begin{array}{c}\text { Biocarbo from } \\
\text { orange peel } \\
\text { BC-OP }\end{array}$ & 421 & 400 & 0.17 & 0.11 & 0.05 \\
\hline $\begin{array}{l}\text { Biocarbon from } \\
\text { cocoa waste } \\
\text { BC-CH }\end{array}$ & 703 & 675 & 0.35 & 0.22 & 0.10 \\
\hline
\end{tabular}

The porous structure of the sample activated at this temperature is investigated by low-temperature nitrogen adsorption at $77 \mathrm{~K}$. The pore structure and the main textural parameters of the samples are presented (Table 2, Fig.2, Fig.3).The results indicate the development of mesoporosity in parallel with microporosity. The presence of hysteresis also confirms the existence of significant amount of mesopores in the test sample. This observation is confirmed by pore size distribution by the DFT method. 

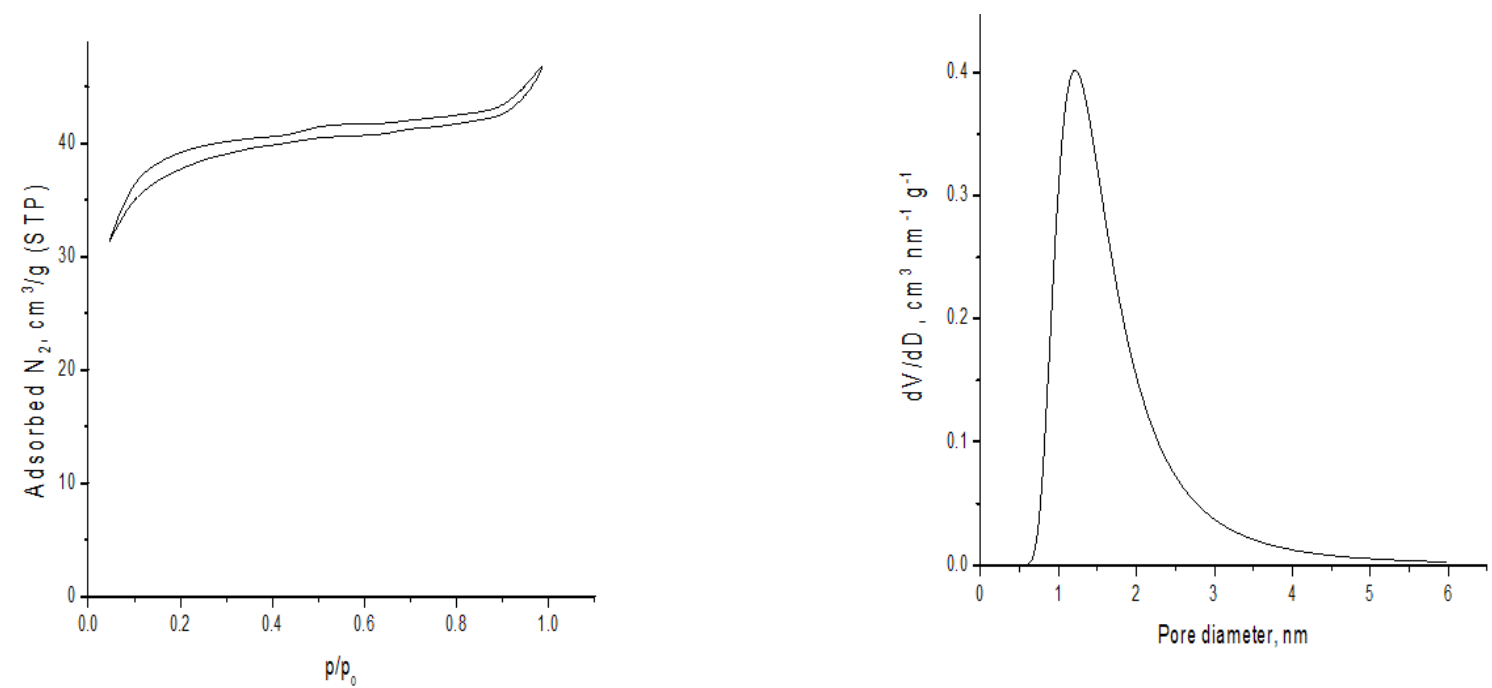

Fig. 2. Nitrogen adsorption isotherm at $77 \mathrm{~K}$ and pore size distribution of biocarbon obtained from orange peel
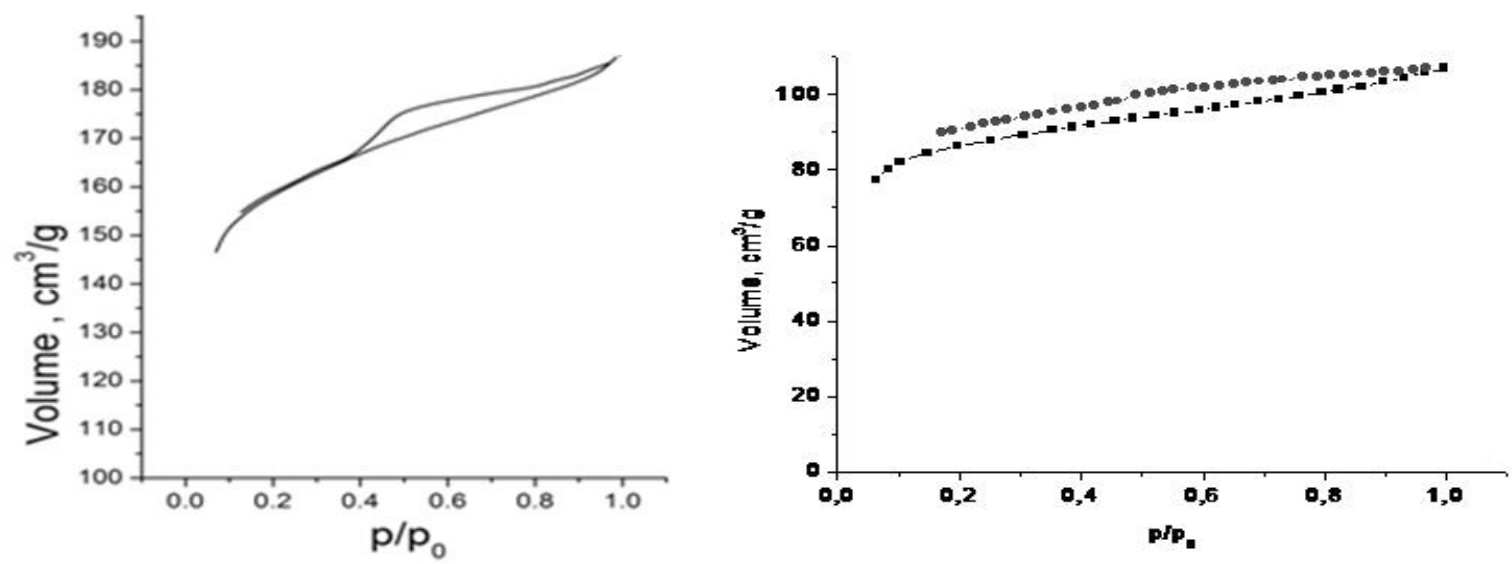

Fig. 3. Nitrogen adsorption isotherm at $77 \mathrm{~K}$ and pore size distribution of biocarbon obtained from cocoa husk and banana peel

\section{CONCLUSIONS}

It was established that thermochemical conversion of lignocellulosic biomass (banana and orange peels, cocoa husk) is a good opportunity to obtain solid product, biocarbon, as well as liquid raw materials for biofuels and biochemicals. The physicochemical and porous properties of biocarbon are suitable for development of effective and inexpensive sorbents for the removal of contaminants from water. The biochars are produced by physical and chemical activation at $500-900^{\circ} \mathrm{C}$. The obtained biocarbons are characterized by moderately high surface area, and high content of micro- and meso-pores, which determine their potential application as adsorbents for water and air purification, catalysts, hydrogen depots, etc.
ACKNOWLEDGEMENT: Authors are grateful for the funding by Project,,Young Scientists and postdoctorants“ DCM No 577 / 17.08.2018 of Bulgarian Ministry of Education, project KP-06-M27/9 and Romanian-Bulgarian Project.

\section{REFERENCES:}

1. Chan, K.Y., Van Zwieten, L., Meszaros, I., Downie, A., Joseph, S., Agronomicvalues of green waste biochar as a soil amendment, Aust. J. Soil Res., Vol. 45, 2007, pp. 629-634.

2. Novak, J.M., Busscher, W.J., Laird, D.L., Ahmedna, M., Watts, D.W., Niandou, M.A.S., Impact of biochar amendment on fertility of a southeastern coastal plain soil, Soil Sci., Vol. 174, 2009, pp.105-112. 
3. Woolf, D., Amonette, J.E., Street-Perrott, F.A., Lehmann, J., Joseph, S., Sustainable biochar to mitigate global climate change, Nature Communications, Vol. 1(5), 2010, 56, DOI:10.1038/ ncomms 1053 .

4. Chen, B., Chen, Z., 2009. Sorption of naphthalene and 1-naphthol by biochars of orange peels with different pyrolytic temperatures. Chemosphere 76, 127-133.

5. Kong, H., He, J., Gao, Y., Wu, H., Zhu, X., Cosorption of phenanthrene and mercury (II) from aqueous solution by soybean stalk-based biochar. $\mathrm{J}$.
Agric. Food Chem. 59, 2011, 12116-12123.

6. Sun, K., Ro, K., Guo, M., Novak, J., Mashayekhi, H., Xing, B., Sorption of bisphenol A, 17alpha-ethinyl estradiol and phenanthrene on thermally and hydrothermally produced biochars. Bioresour. Technol. Vol. 102, 2011, 5757-5763.

7. Chen, X., Chen, G., Chen, L., Chen, Y., Lehmann, J., McBride, M. B.; Hay, A.G. Adsorption of copper and zinc by biochars produced from pyrolysis of hardwood and cornstraw in aqueous solution, Bioresource technology, Vol. 102, 2011, 8877-8884.

\section{Kalina Miteva, Georgi Georgiev, Ivanka Stoycheva, Nartzislav Petrov, Bilyana Petrova,}

Institute of Organic Chemistry with

Centre of Phytochemistry, BAS,

9, Acad. G. Bonchev str., BL

Sofia 1113, Bulgaria

\section{Andrei Sarbu, Boyko Tsyntsarski,}

National Research- Development Institute for

Chemistry and Petrochemistry INCDCP-ICECHIM,

Spl. Independentei 202, sector 6,

Bucharest, Romania 